\title{
FIELD TESTS ON SEA DEFENCES SUBJECT TO WAVE OVERTOPPING
}

\author{
Gert Jan Akkerman ${ }^{1}$, Patrizia Bernardini ${ }^{2}$, Jentsje van der Meer ${ }^{3}$, Henk Verheij ${ }^{4}$ \\ and André van Hoven ${ }^{5}$
}

\begin{abstract}
As a response to ongoing sea level rise, crest levels of sea defences need to be raised in future at huge expenditure and with increased risk. As an alternative, dikes can be strengthened as to accommodate for increased wave overtopping. Within the ComCoast program (a European project between governments along the North Sea for innovative solutions for the safety of sea defences) research has been done on overtopping-resistant sea defences and ideas for different types of reinforcements have been generated. A concept with a specific geosynthetic that reinforces the crest and inner slope of the dikes was awarded for installation at a sea dike in the Netherlands in 2006. The actual field tests took place early 2007. These tests are unique in their kind as they have been carried out on a real dike under full scale wave overtopping conditions, far beyond present standards. As a result, the erosive impact of wave overtopping on the natural grass covered dike section, on the reinforcement section, as well as on a bare clay layer section, has been investigated under representative wave overtopping conditions. This paper describes the results of these field tests, i.e. the strength response of the dike slopes and indicates the follow-up and potentials of the results obtained thus far.
\end{abstract}

\section{INTRODUCTION}

A major aim of the ComCoast project is to develop wide coastal zones with the possibility of increased wave overtopping under extreme conditions. This will allow for a multifunctional coastal zone to be created, that is adaptive to occasional accommodation of sea water. Such a spatial adaptation offers opportunities for salt or brackish ecosystems, recreation, living and wet agriculture.

A prerequisite for such a wide coastal zone is to reinforce the crest and inner slope of the dikes to such an extent that increased amounts of wave overtopping can be allowed as an alternative to continuous increase of the crest level of the dike. Prior to the field tests, a grass reinforcement, denoted Smart Grass Reinforcement, abbreviated SGR, had been developed by the consortium (Van Gerven et al., 2005) and this system was installed at the dike test section in 2006 (Van Gerven et al., 2006), see www.comcoast.org.

The major ComCoast-formulated goal of the tests is to check the performance of the SGR, as compared to the natural grassed slope. These erosion tests have been carried out early 2007 (Akkerman et al., 2007), see www.comcoast.org. In addition to the ComCoast program, the Dutch SBW program in which sea defence behaviour is studied in-depth, supported these tests.

\footnotetext{
${ }^{1}$ Royal Haskoning, P.O. Box 151, 6500 AD, Nijmegen, NL, gj.akkerman@royalhaskoning.com

${ }^{2}$ Rijkswaterstaat, Waterdienst, P.O. Box 5044, 2600 GA, Delft, NL, patrizia.bernardini@rws.nl

${ }^{3}$ Van der Meer Consulting, P.O. Box 423, 8440 AK, Heerenveen, NL, jm@vandermeerconsulting.nl

${ }^{4}$ Delft Hydraulics/ Deltares, P.O. Box 177, 2600 MH, Delft, NL, henk.verheij@wldelft.nl

${ }^{5}$ GeoDelft / Deltares, P.O. Box 69, 2600 AB, Delft, NL, a.vanhoven@geodelft.nl I
} 
Wave overtopping erosion tests cannot be scaled down well in physical scale models. Hence, tests have to be carried out in a large wave tank or in a real situation. The latter is to be preferred, as the condition of the dike remains undisturbed and the costs for constructing an 'undisturbed' dike section in a wave tank are excessive. The field tests on the sea dike in Groningen, the most northern province of the Netherlands, are unique in their kind as such tests have not yet been carried out thus far. The simulation of the full scale wave overtopping could be realized by a special device that was developed within the present research framework: the wave overtopping simulator, based on the idea of Dr. J.W. van der Meer.

The erosion tests gave important information about the reference strength of the naturally grassed dike. In addition, surface erosion at a bare clay section was tested as well as to obtain insight in the residual strength of the clay when the grass cover would be removed unexpectedly by wave overtopping. For these tests, $20 \mathrm{~cm}$ of the grass cover had been removed.

\section{FULL SCALE WAVE OVERTOPPING}

A full description of the wave overtopping simulator has been given in the CSt07 paper by Van der Meer et al., 2007. Here, the major topics of the wave overtopping simulator will be dealt with, with reference to the afore mentioned paper for more details.

The idea behind the wave overtopping simulator is that the wave overtopping can be reproduced well without reproduction of the waves at the seaside of the dike. Typically, at sea defences that are designed for severe wave overtopping, the overtopping waves manifest themselves as wave tongues that pass the crest in a random way. The characteristics of the wave tongues at the crest of the dike is known quite well from comprehensive research. This enables the reproduction of the wave tongues at the dike crest, without reproducing the waves that cause the overtopping. Hence, the wave overtopping simulator can basically be a large water tank that is placed above crest level at the dike to be tested and that can release controlled volumes of water. These volumes flow out at the crest of the dike and at the inner slope in a controlled way, reproducing the right flow forces at the crest and at the inner slope. The total required volume of overtopping water is obtained by pumping the specific (time-averaged) overtopping discharge into the tank at a constant rate. The flow distribution can be simulated by releasing water volumes at predetermined times that relate to a specific volume of the water in the tank.

After adequate testing of a prototype of the simulator with a width of $1 \mathrm{~m}$, including calibration of a large number of parameters, the $4 \mathrm{~m}$ wide final simulator was constructed. This simulator performed well during the trial tests on the sea dike and thus was considered ready to be deployed at the field tests 
after minor adaption. During the full testing program of about some 5 weeks, the wave overtopping simulator performed very well indeed.

The overtopping discharges could be varied within a wide range: from $0.1 \mathrm{l} / \mathrm{s}$ per $\mathrm{m}$ to about $50 \mathrm{l} / \mathrm{s}$ per $\mathrm{m}$, the latter overtopping discharge being far beyond present overtopping standards.

An impression of the simulator during maximum wave overtopping is given in Figure 1 below.

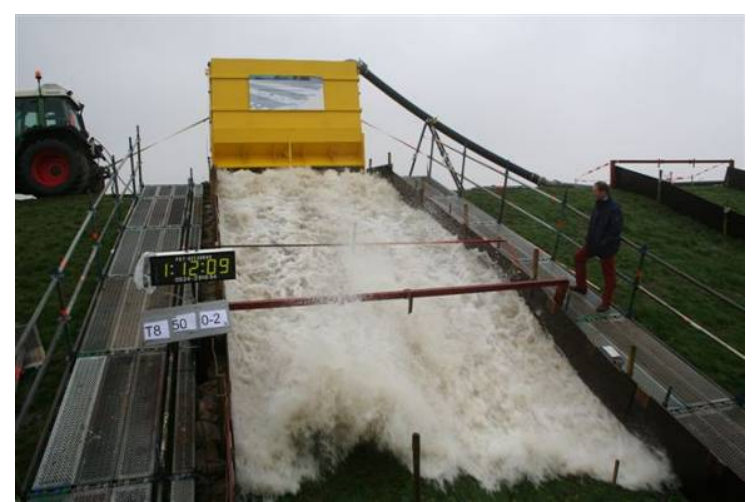

Figure 1. Wave overtopping simulator during the field tests on the sea dike, releasing a maximum wave volume of $3.5 \mathrm{~m}^{3}$ per $\mathrm{m}$ width in a few seconds.

\section{GRASS REINFORCEMENT SYSTEM}

The grass reinforcement system was elaborated by the Royal Haskoning \& Infram consortium after consideration of a wide variety of reinforcement systems (Van Gerven, 2005). This reinforcement system was the winning concept during a contest that was issued within the ComCoast program. This system consists of a 3-dimensional specifically selected geosynthetic placed underneath the grass surface. This reinforced grass system was denoted 'Smart Grass 'Reinforcement' (SGR). After placement this system enables optimum root penetration and intertwinement of the grass roots and, at the same time, provides sufficient shelter to the under laying substrate when uncovered. In addition, the strength and stiffness of the system is such that shear forces can be dissipated well by the geosynthetic. The selection of this system followed after an extensive functional analyses of the specifications for the SGR, with sometimes contradictory demands. The system selected, the Fortrac 3D-120 system by Huesker Synthetic, fulfilled these demands best. An impression of the geosynthetic is given in Figure 2, from which the 3-dimensional character can clearly be seen. 


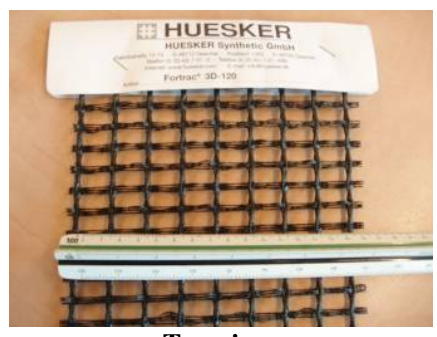

Top view

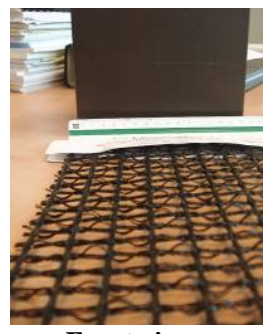

Front view

Figure 2: Selected Fortrac 3D-120 system for reinforcement of dike crest and inner slope

An innovative aspect of the SGR reinforcement is that the geosynthetic is placed underneath the upper grass layer. The SGR can be referred to as 'smart' because it fulfills a large number of requirements such as:

- Provision of significant reinforcement to the grass revetment

- Easy installation of the geosynthetic at the existing grass cover with minimum disturbance and without the necessity to grow new grass

- Strong, strain-insensitive and flexible geosynthetic

- High cost-effectiveness of total concept

- Invisible

- Durable

- $\quad$ No adverse environmental impacts

Strength improvement by the presence of the SGR may not be limited to improvement of surface erosion resistance, but will most likely also contribute to mitigation of other failure mechanisms such as shallow slip failure and internal erosion.

The placement technique to install the geosynthetic in an adequate way underneath the grass cover is still subject to further detailing and engineering, as only the conceptual idea could be developed within the ComCoast program. This concept implies the deployment of a machine that cuts the grass at some distance below the surface and lifts the upper grass cover temporarily while placing a geosynthetic at the same time underneath this cover, as shown in Figure 3. In passing, the lifted grass cover is guided back to its original position, which is feasible due to the elasticity in the grass sod. 


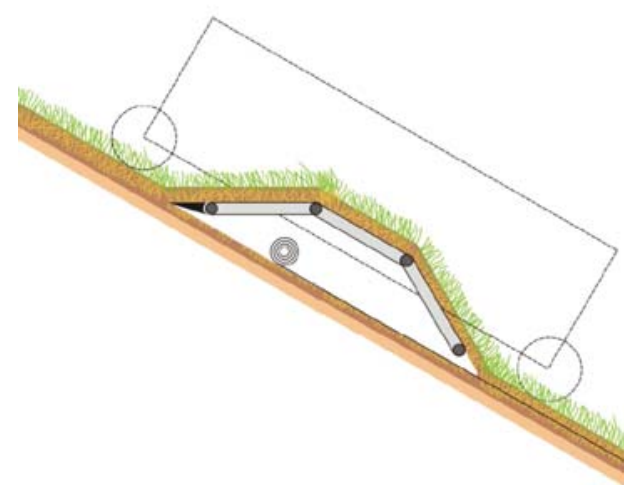

Figure 3: schematical sketch of placement of the geosynthetic in upward direction

For the field tests this methodology was not engineered further to the extent required for proper placement. Hence, another way of placement was adopted: cutting the grass with a small thickness $(0.05 \mathrm{~m})$ in $1 \mathrm{~m}$ wide strips and winding the grass cover to 'big rolls'. After installation of the geosynthetic, these rolls were replaced with a crane and the grass was unwound. This type of installation had a highly exploratory character, as it had not been done before. Hence, the installation was preceded by an extensive analysis of risk factors and mitigation measures for placement. In May 2006 the 4 m wide SGR test section was installed at the sea dike according to this methodology. An impression of this method, denoted as Big Roll method, is given in Figure 4.

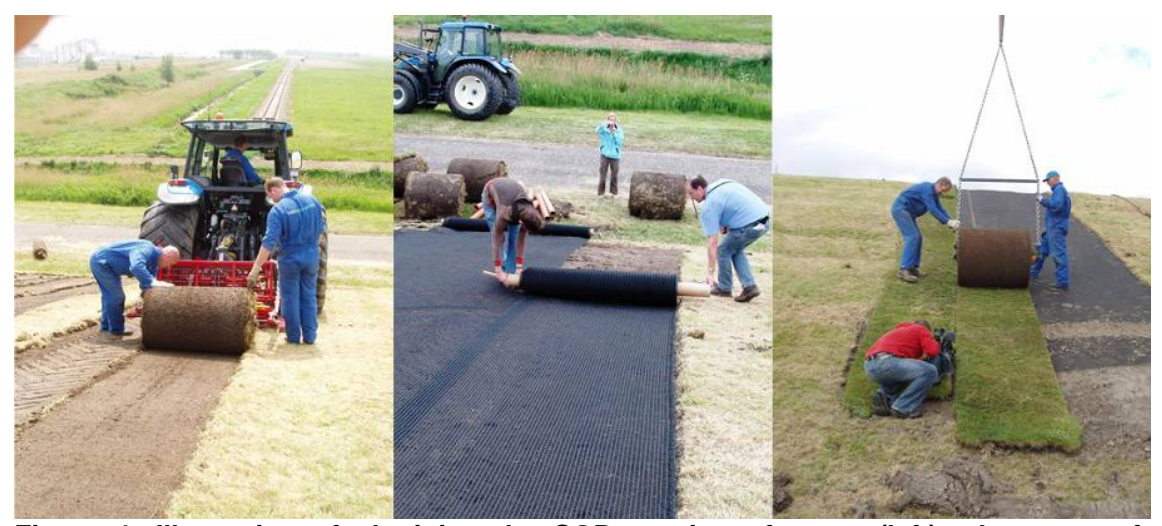

Figure 4: Illustration of obtaining the SGR: cutting of grass (left), placement of geosynthetic (middle) and unwinding of the big rolls (right)

The Big Roll method was not ideal, as the grass cover suffered considerably during the whole placement, which took 2 days. However, the grass recovered quite well after one growing season, after receiving after-treatment, such as 
sprinkling and fertilization. For comparison reasons, the natural grass test section, also received the same after-treatment.

Prior to the tests early 2007, some samples with SGR were dug up and the grass roots showed a root penetration and intertwinement as anticipated, as can be seen in Figure 5. This encouraging result was obtained within one growing season.

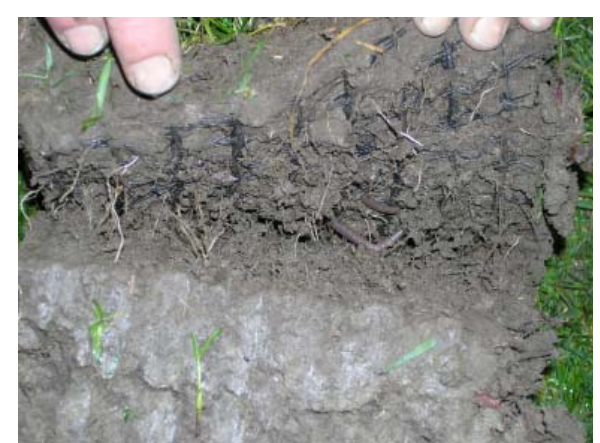

Figure 5: Root penetration of grass roots and intertwinement of geosynthetic

\section{FIELD EROSION TESTS}

\section{Test set-up}

The erosion field tests on the SGR and the natural non-reinforced grass sections at the Groningen sea dike were carried out February and March 2007. This timing was chosen such that the grass was at winter condition. The tests were carried out by the consortium of Royal Haskoning \& Infram. In addition, an erosion test on bare clay was carried out as well. The test set-up and results have been described in-depth by Akkerman et al., 2007, see www.comcoast.org. This report also includes summaries of additional investigations (geotechnical, grass, saturation) and provides as a preliminary analysis of the results.

An impression of the test set-up is shown in Figures 6 and 7.

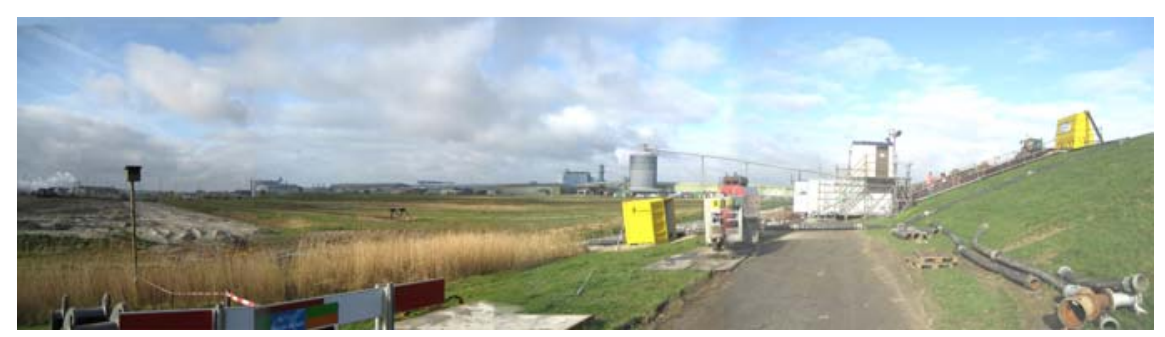

Figure 6: Wide angle view of test set-up at the inner slope of the Groningen sea dike 


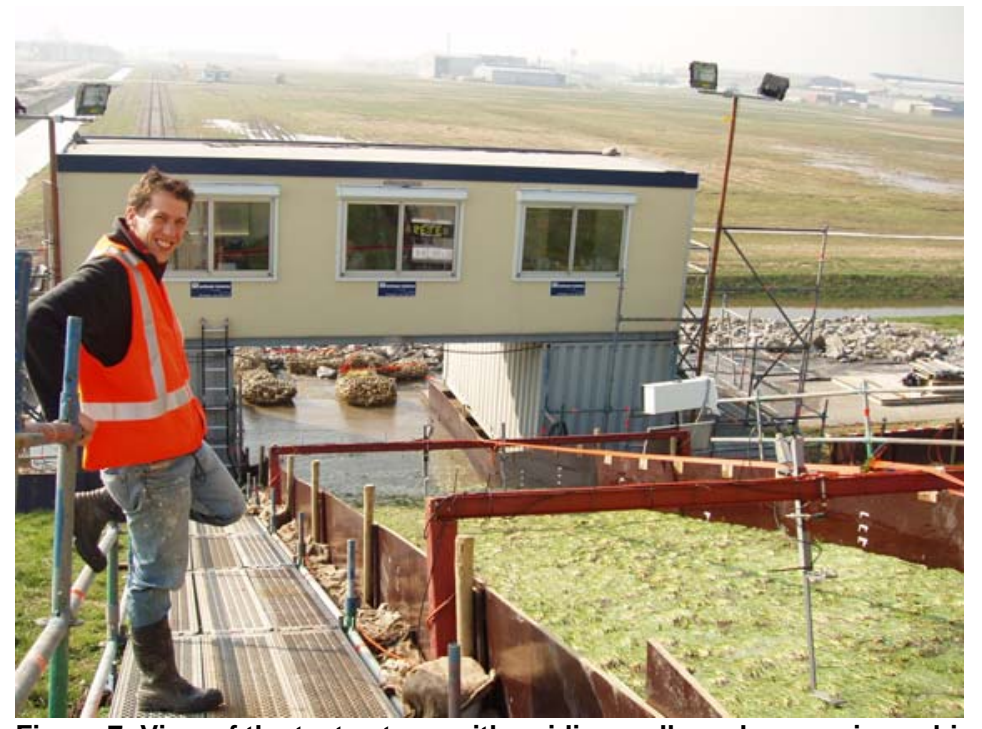

Figure 7: View of the test set-up, with guiding walls and measuring cabin

The erosion tests focused on observation of surface erosion behaviour of the grass cover and under laying clay substrate exposed to the wave overtopping. In addition, water velocities and water depths of the overtopping tongues were measured. As these measurements had a direct relation with the performance of the wave overtopping simulator, they have been reported in the CSt07 paper of Van der Meer, 2007, as well as in the separate ComCoast report on the wave overtopping simulator by Van der Meer, 2007. After analysis, these measurements proved to be erroneous, probably due to the high turbulence and aeration of the flow. The analysis has also been presented in the MSc thesis by Bosman, 2007.

The whole test arrangement was shifted from the non-reinforced to the reinforced (SGR) section, and finally to the bare clay section. For quality assurance, safety control and risk mitigation a comprehensive measuring protocol was set up.

The damage progress during the simulated 6-hour peak of a storm was continuously filmed and photographed and measured with intervals of 2 hours. At each test section, 6-hour subsequent storm peaks with increasing overtopping discharges were simulated in real-time (except for the first storm which was speeded up 10-fold), i.e.:

- 6 hours storm peak with overtopping discharge of $0.1 \mathrm{l} / \mathrm{s}$ per m;

- 6 hours storm peak with overtopping discharge of 1 l/s per m;

- 6 hours storm peak with overtopping discharge of $10 \mathrm{l} / \mathrm{s}$ per m;

- 6 hours storm peak with overtopping discharge of $20 \mathrm{l} / \mathrm{s}$ per m;

- 6 hours storm peak with overtopping discharge of $30 \mathrm{l} / \mathrm{s}$ per m; 
- 6 hours storm with overtopping discharge of $50 \mathrm{l} / \mathrm{s}$ per m;

The latter test had been improvised as to extend the range of testing. This test may not have been fully representative, as the maximum overtopping volumes of the $50 \mathrm{l} / \mathrm{s}$ per $\mathrm{m}$ storm $\left(6.4 \mathrm{~m}^{3}\right.$ per $\left.\mathrm{m}\right)$ could not be reproduced due to the limited capacity of the simulator. Instead, the number of largest wave that could be reproduced ( $3.5 \mathrm{~m}^{3}$ per $\mathrm{m}$, corresponding to the $30 \mathrm{l} / \mathrm{s}$ per $\mathrm{m}$ rate) was increased such as to arrive at the right total sum of overtopping volumes that corresponded to the $50 \mathrm{l} / \mathrm{s}$ per $\mathrm{m}$ rate. The detailed procedure for this test has been described in the CSt07 paper of Van der Meer, 2007.

The tests followed a strict protocol, that envisaged uncertain conditions, such as: unworkable weather, other delays and unexpected results.

\section{EROSION TEST RESULTS}

The erosion tests showed remarkable results in that sense that the natural grass section, as well as the non-reinforced grass section, showed a much better erosion resistance than anticipated. After a week of testing up to the overtopping discharge of $30 \mathrm{l} / \mathrm{s}$ per $\mathrm{m}$, the grass covers were still intact. It should be noted here that some of the loose turf had been removed by the overtopping action, but the majority of the grass sods were still in place. Even at the highest overtopping discharge of 50 l/s per m no major damage could be observed.

Hence, it was decided to introduce some damage to the test sites and to repeat the $50 \mathrm{l} / \mathrm{s}$ per $\mathrm{m}$ test. Different types of damage had been applied to the inner slope (small holes, two major bare spots, placement of poles and pickets). After testing, a marked difference could be observed between the natural grass section and the SGR section. This is illustrated in Figure 8 which shows the damage patterns after completion of the $50 \mathrm{l} / \mathrm{s}$ per $\mathrm{m}$ test.

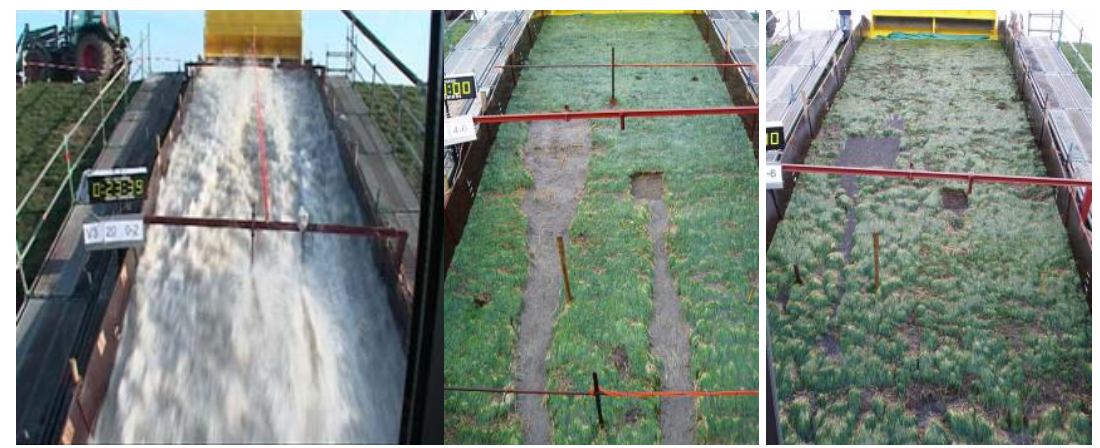

Figure 8: Damage pattern at the natural grass section (middle) and the SGR section (right), showing differences in damage progression after $50 \mathrm{l} / \mathrm{s}$ per $\mathrm{m}$

At the non-reinforced section, gullies had developed, which extended to the toe of the dike, whereas at the SGR section gully formation was virtually absent. 
This can be explained from the presence of the SGR, by which the grass layer is successfully reinforced with the geosynthetic. The strength improving action could be observed from the grass roots that 'anchored' very well to the geosynthetic, as is illustrated in Figure 9.

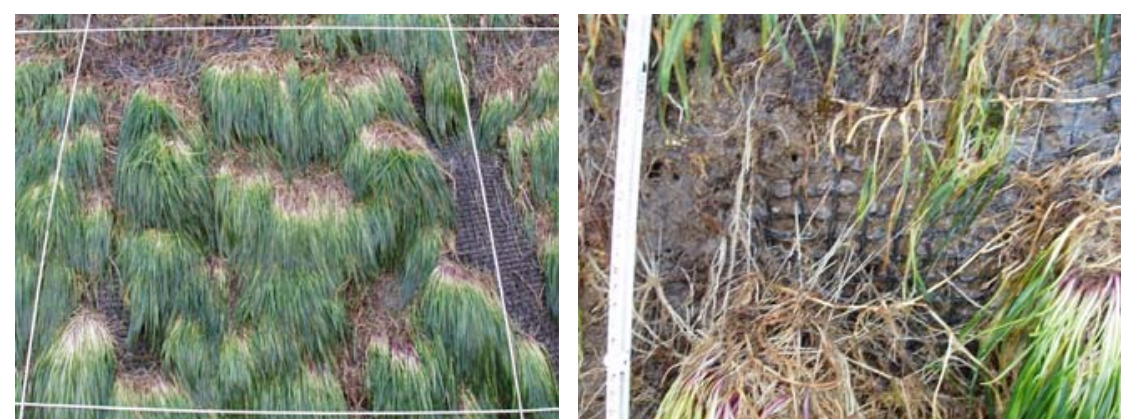

Figure 9: Anchoring of the grass sods to the geosynthetic, even at bared spots

Finally, the erosion resistance of the bare clay section was investigated. Here, the absence of grass was clearly noticeable, as damage already occurred at the 1 $\mathrm{l} / \mathrm{s}$ per $\mathrm{m}$ test. After performing an intermediate test with $5 \mathrm{l} / \mathrm{s}$ per $\mathrm{m}$, a final test of $10 \mathrm{l} / \mathrm{s}$ per $\mathrm{m}$ showed severe erosion of the inner slope. This erosion manifested itself with distinct scour holes and steep cliffs. This erosion progressed towards the crest of the dike. The deepest hole was about $1 \mathrm{~m}$ deep, as is shown in Figure 10. From literature, this cliff type of erosion was to be expected.
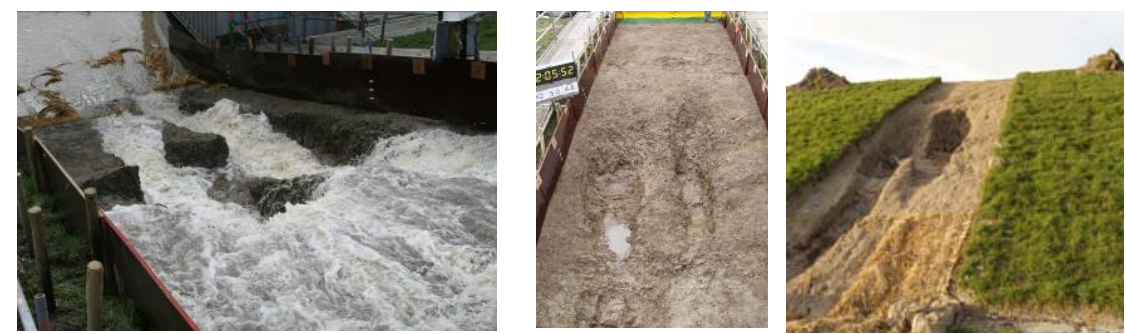

Figure10: Impression of the erosion at the bare clay section directly after testing (middle) and after removal of the test equipment (right).

From saturation measurements it could be observed that the clay was rather permeable, in spite of the good clay quality. This was possibly caused by numerous worm holes and small fissures that crisscrossed the clay layer.

This test demonstrated the decisive influence of grass at the slope in preventing severe erosion of the subsoil. The geosynthetic of the SGR actually works in the same way: helping to keep the grass in place under severe overtopping conditions. At the same time, it must be acknowledged, that the residual strength 
of the bare clay layer is still significant and greater than anticipated thus far. It should be remarked here that the core of the test dike was constructed with massive clay. As opposed, many dikes in the Netherlands have a sand core that is covered with a clay layer of $1 \mathrm{~m}$ or less. This situation may be much more vulnerable for erosion than the dike section tested here.

\section{FOLLOW UP OF THE TESTS AND POTENTIALS}

The promising results of these erosion tests, have triggered the planning of an extensive field test program that will be performed at sea dike locations in different provinces of the Netherlands. These tests will be carried out within the framework of the sea defence research program SBW, initiated by the Dutch Ministry of Transport and Public Works. These follow-up tests will start early 2008 and will continue for several years at four locations in the Netherlands. The test conditions will be varied largely and will encompass the influence of maintenance of the grass cover. Apart from surface erosion of the grass cover at the crest and inner dike slope, shallow slip failure will be tested under wave overtopping conditions as well as under conditions of over-saturation.

The results will be used for upgrading the Dutch overtopping standards in 2011, based on a thorough understanding of the phenomena associated with wave overtopping. During these tests, shallow slip failure will also be taken into account. In 2009 and 2010 tests are foreseen at a special site in the Netherlands where dikes can be investigated up to and including breaching: the 'Calibration Dike' location in the province of Groningen, where a special test basin with test dikes is constructed. Focus will be put on elaborating innovative monitoring techniques. In addition, the SGR will be tested there more in-depth.

Some impression of the Calibration dike program are given in Figure 11, see also http://www.inspectiewaterkeringen.nl/documents/inspectiewaterkeringen/downloads/ brochure\%20ijkdijk_engels.pdf. 

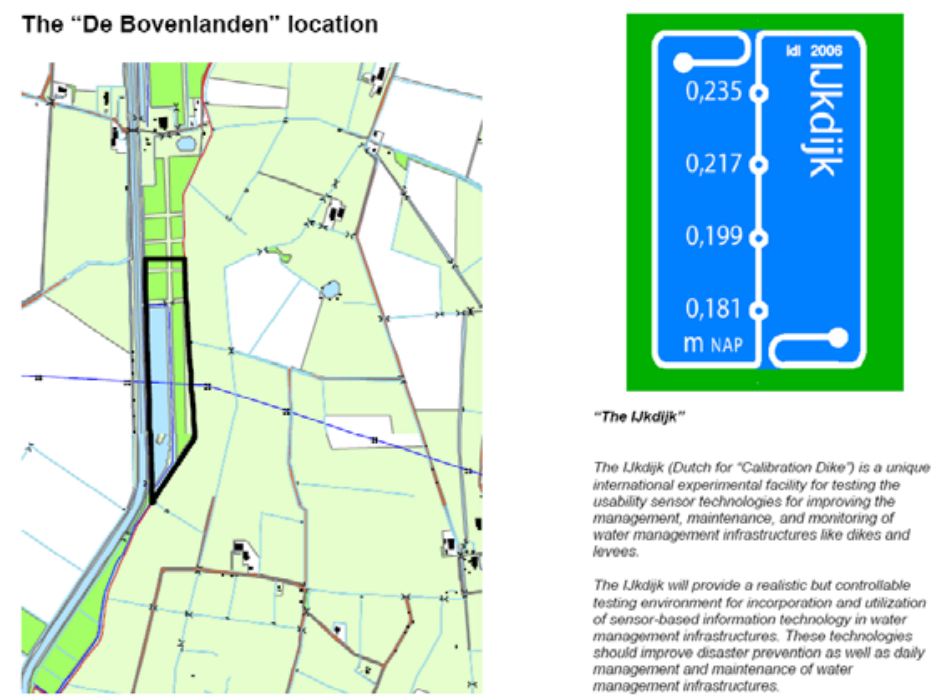

Figure11: Impression of the Calibration dike facility in the Netherlands

In the meantime activities are ongoing to make the SGR operational for large scale application. Special focus is put on further improvements of the installation system in coherence with the geosynthetic.

\section{CONCLUSIONS AND RECOMMENDATIONS}

The results of the field tests have shown that present sea dikes can be much more resistant to wave overtopping than assumed thus far, even without reinforcement. This seems to contradict to earlier experience in the Netherlands during the flooding disaster in 1953, during which many of the breaches initiated from superficial sliding of the inner slope, leaving the dike core unprotected against erosion. However, those failed dikes had steep inner slopes (generally 1:2 or steeper). These slopes have been flattened since to 1: 3 or less. Moreover, the outer slopes have been flattened further which adds to the wave overtopping resiliency.

Strengthening of the grassed crest and inner slopes of dikes with the SGR will further increase the erosion resistance. A major function of the SGR is to increase the resiliency of dikes against weak local spots, e.g. by poor grass or damage. At non-reinforced slopes this may lead to initial failure of the grass cover and progressive gully formation, as was observed during the tests, finally leading to failure. Applying a SGR may prevent this initial failure and extend this onset of stability to higher levels of wave overtopping. It should be noted here that the total strength of a sea dike is dependent on all relevant failure mechanisms, of which surface erosion is just one mechanism. However, we 
think that the SGR will also be able to mitigate other failure mechanisms, such as shallow slip failure and internal erosion.

In regard of the potential benefits of the SGR we recommend to perform further field tests with the SGR, beyond the scope of the Calibration dike program and at shorter notice. Such research may apply to river dike strengthening, with predominant overflow rather than wave overtopping, to other SGR systems and to other types of dikes. We think that the benefits of the SGR will even be relatively larger in (semi-) arid areas, than in moderate climates, as the SGR may effectively mitigate cracking and drying out of clay layers during extreme droughts.

\section{REFERENCES}

Akkerman, G.J., P. Bernardini, J.W. van der Meer, H. Verheij, A. van Hoven, 2007-1. Field Tests on Sea Defences Subject to Wave Overtopping. ASCE, proc. Coastal Structures CSt07, Venice, Italy.

Akkerman, G.J, K.A.J. van Gerven, H.A. Schaap and J.W. van der Meer, 2007-2. Wave Overtopping Erosion Tests at Groningen Sea Dike. ComCoast, Workpackage 3: Development of Alternative Overtopping-Resistant Sea Defences, phase 3. See www.comcoast.org.

Bosman, G., 2007. Velocity and flow depth variations during wave overtopping. MSc-thesis Delft University of Technology.

Van der Meer, J.W., 2007-1. The Wave Overtopping Simulator in Action. ASCE, proc. Coastal Structures CSt07, Venice, Italy.

Van der Meer, J.W., 2007-2. Design, construction, calibration and use of the wave overtopping simulator. ComCoast, Workpackage 3: Development of Alternative Overtopping-Resistant Sea Defences, phase 3. See www.comcoast.org.

Van Gerven, K.A.J., G.J. Akkerman, 2006. Placement of smart grass reinforcement at Test Sections Groningen Sea Dyk. ComCoast Workpackage 3: Development of alternative overtopping resistant sea defences, phase 3. See www.comcoast.org.

Van Gerven, K.A.J., J.W. van der Meer, M.A. van Heereveld, G.J. Akkerman, 2005. Elaboration of Smart Grass Reinforcement Concept. ComCoast Workpackage 3: Development of alternative overtopping resistant sea defences, phase 2. See www.comcoast.org. 
KEYWORDS - CSt07

Abstract acceptance number 215 (in book of abstracts)

FIELD TESTS ON SEA DEFENCES SUBJECT TO WAVE OVERTOPPING

Akkerman, Gert Jan

Bernardini, Patrizia,

Van der Meer, Jentsje W.,

Hoffmans, Gijs J.C.M.

Erosion

Wave Overtopping

Grass slope

Grass reinforcement

Clay slope

Dike

Levee

Embankment 